\title{
Evaluation of highly filled epoxy composites modified with walnut shell waste filler
}

\author{
Kamila Salasinska ${ }^{1}$ - Mateusz Barczewski ${ }^{2}$. \\ Rafał Górny $^{1} \cdot$ Arkadiusz Kloziński $^{3}$
}

Received: 17 March 2017 / Revised: 18 July 2017/Accepted: 18 August 2017/

Published online: 29 August 2017

(C) The Author(s) 2017. This article is an open access publication

\begin{abstract}
Epoxy composites modified with ground walnut shell used as organic waste fillers were prepared and examined. Post-agricultural waste materials after grinding were characterized by evaluation of grain size distribution and structure observations realized using scanning electron microscope (SEM). The influence of filler addition on the mechanical properties of epoxy-based composites was determined by: static tensile test, Charpy impact test, and ball indentation hardness measurements. Composite samples containing 20,30,40, and $50 \mathrm{wt} \%$ of walnut shell were characterized by increased stiffness and hardness in comparison to the unmodified resins. Moreover, the incorporation of the filler resulted in a decrease of composite material tensile strength and impact resistance. Thermo-mechanical properties of the composites were investigated by dynamic mechanical thermal analysis (DMTA). Results obtained from DMTA tests showed a growth in the composites' stiffness at elevated temperatures as a function of the increasing natural filler content. The material characterization was supplemented by thermal stability evaluation realized by thermogravimetric analysis (TGA). It was found that the incorporation of ground walnut shell led to an improved thermal stability of composite materials. The analysis of the change in composite material properties, caused
\end{abstract}

Kamila Salasinska

kasal@ciop.pl

$凶$ Mateusz Barczewski

mateusz.barczewski@put.poznan.pl

1 Department of Chemical, Biological and Aerosol Hazards, Central Institute for Labour Protection - National Research Institute, Czerniakowska 16, 00-701 Warsaw, Poland

2 Institute of Materials Technology, Poznan University of Technology, Piotrowo 3, 61-138 Poznań, Poland

3 Institute of Chemical Technology and Engineering, Poznan University of Technology, Berdychowo 4, 60-965 Poznań, Poland 
by natural filler incorporation, was complemented by material microstructure observations.

Keywords Composite · Natural filler · Epoxy resin · Walnut shell $\cdot$ Mechanical properties

\section{Introduction}

The purpose of fillers introduced into polymers is to reduce costs, improve the processing properties, and achieve a change in material properties to mention only increase in stiffness and strength [1] as well as improved thermal resistance or conductivity [2, 3]. Polymer composites modified with natural fillers are an alternative to traditional materials, such as wood and its substitutes (chipboard, fiberboard, plywood), as well as so-far used polymer composites modified with inorganic fillers. The unquestionable advantage of natural organic fillers is their availability (the possibility of acquiring raw materials from any part of the locally occurring plants), renewability, and relatively low cost which contributes to a reduced end-product price [4]. It was proved that financial resources necessary to obtain plant material may be twice lower compared with glass fiber, even four times in relation to the aramid fiber, and up to five times to the carbon fiber [5, 6]. Moreover, natural fillers especially powder-like are further characterized by significantly lower energy consumption needed for their manufacturing [7]. Several advantages resulting from the replacement of inorganic and synthetic fillers with organic materials for composite material production should be specified: low density, natural origin, satisfactory mechanical properties, high vibration damping ability, and good thermal insulation [5, 8].

According to the data presented by Nova-Institut GmbH and Asta Eder Composite Consulting, the production of polymer composites modified with natural fillers named wood-plastic composites (WPC) and natural fiber composites (NFC) reached 352,000 $\mathrm{t}$ in European Union (EU) in 2012 which represents almost $15 \%$ of the European composite market. Natural fillers used as a reinforcement of polymer composites can be extracted from stems, leaves, fruits, as well as lignified parts of plants (seeds, husks, hulls) [5]. Wood flour and cotton fibers, whose share on the European market is 54 and $32 \%$ respectively, are the most common natural fillers used in industrial practice [9]. The remaining $14 \%$ includes various types of fiberlike fillers of which the most popular are: flax (64\% share of the NFC market in the EU with fillers other than wood and cotton), jute (11\%), hemp (10\%), and sisal (7\%) [9, 10]. Various plant fillers used for natural composite production, such as: bamboo, coconut, kenaf, ramie, nettles, abaca, pineapple, sugar cane, rice, and grass, can be found in the literature and industrial applications [10-12]. Except for the specially prepared fiber-like natural fillers (e.g., bamboo, kenaf, jute, and flax), great attention is placed on the incorporation of agricultural waste materials into polymeric matrix. Lignified parts of agricultural plants in the form of various types of shells and husks have become valuable products to be used in composite 
modification processes due to their high availability and scarce interest of other industrial sectors i.e., energy and biochemical industry (production of biopolymers) $[4,13,14]$. It is noteworthy that despite the fact that natural composite material production in the EU is third in the world, many NFC products are still imported from the United States and China which are the biggest producers of this kind of assortment [15]. Therefore, finding new low-cost composite materials based on regional natural fillers, especially from agricultural industry, seems more than reasonable. Numerous publications describing composites with the abovementioned fillers are a good proof of the vast applicability of natural composites modified with post-agricultural waste fillers [16-18]. On the basis of economic analysis accounting for its availability and cost of subsequent preparation to be applied as a polymer filler (including grinding and drying), it was found that the price of $1 \mathrm{~kg}$ of ground walnut shell obtained in Poland (Central Europe) in 2017 is about 0.12 USD. Therefore, the application of this type of filler in case of low-cost composites can be justified.

The aim of this study is to develop and characterize composites based on epoxy resin highly filled with post-agricultural waste material. Available and inexpensive waste material in the form of ground walnut shell was used as a filler instead of wood flour. It should be underlined that several studies focusing on the application of walnut husks as a filler in thermoplastic and thermoset composites can be found in the literature [19-22]. However, the amount of natural reinforcement used in polymer matrix usually did not exceed $25 \mathrm{wt} \%$. The presented studies include detailed descriptions of filler preparation and characterization, as well as composite production procedure. Composite materials containing different amounts of natural filler were subjected to a series of tests comprising: static tensile test, impact resistance and hardness measurement, dynamic mechanical thermal analysis, as well as thermal stability evaluation. The influence of the filler addition on epoxy composite properties was supplemented by microstructure observations and FT-IR spectroscopic analysis. The main objective of this research was to determine the possible applications and limitations of highly filled thermoset composite materials modified with an organic waste filler coming from the agricultural industry. Attempts were made to determine if and how the features of the ground walnut shell (geometry, chemical constitution, water content) affect the curing process, mechanical and thermo-mechanical properties, and also thermal stability of the composites. To better investigate the relationship between the features of the components and the composites' properties, no additional modifiers and adhesion promotes were incorporated to the mixtures.

\section{Experimental}

\section{Materials}

Epidian 624 epoxy resin, based on bisphenol A (BPA, epoxy number $0.48-0.51 \mathrm{~mol} / 100 \mathrm{~g}$, viscosity $600-800 \mathrm{mPa} \mathrm{s}$, density $1.11 \mathrm{~g} / \mathrm{cm}^{3}$ ), and isophorone diamine curing agent (IDA, amine number $250-350 \mathrm{mg} \mathrm{KOH} / \mathrm{g}$, viscosity 
150-300 mPa s, density $1.02 \mathrm{~g} / \mathrm{cm}^{3}$ ), both produced by CIECH Sarzyna S.A.(Poland), were used as polymer matrixes. Composition ingredients were proportioned by weight: $50 \mathrm{wt} \%$ of curing agent for $100 \mathrm{wt} \%$ of epoxy resin. Pot life of the composition was ca. 50 min. Walnut husk (Juglans regia Species, WS) obtained from AGRO Jarosław Seroczyński (Poland) was used as a lingo-cellulosic postagricultural waste filler.

\section{Sample preparation}

Preparation involved grinding of the filler was carried out on a laboratory mill sieve type MUKF-10 (Młynpol, Chwaszczyno, Poland). During the milling process, sieve mesh with a size of $0.2 \mathrm{~mm}$ was used. Next, the drying process was performed using Plus II Incubator (Gallenkamp, Loughborough, Great Britain). The drying time at a temperature of $40 \pm 2{ }^{\circ} \mathrm{C}$ was 7 days. Additionally, a drying process at a temperature of $60 \pm 2{ }^{\circ} \mathrm{C}$ and time $24 \mathrm{~h}$ was carried out before the production of the composites.

Mixing of the natural components with the resin was carried out using a highspeed mechanical stirrer with a water jacket (CILP-NRI, Warsaw, Poland). Observations conducted during the mixing showed that the solution prevented excessive temperature rise and the maximum temperatures during mixings not exceeded $43{ }^{\circ} \mathrm{C}$. The natural filler of $20-50 \%$ by weight was introduced into the epoxy resin and stirring was performed using three rotational speeds: 7000, 10,000, and 17,000 rpm; which were applied for 3, 1.5, and $0.5 \mathrm{~min}$, respectively. Subsequently, the mixture was degassed at a temperature of about $25^{\circ} \mathrm{C}$ for $30 \mathrm{~min}$, using a laboratory vacuum dryer Goldbrunn 1450 (GOLDBRUNN THERM, Zielona Góra, Poland). Then, IDA curing agent was added, the components were stirred again for $2 \mathrm{~min}$ at a speed of $7000 \mathrm{rpm}$ and degassed in a vacuum dryer for $10 \mathrm{~min}$. Normalized specimens were formed by casting into heated forms coated with a resolving agent. The cast samples were conditioned after curing at room temperature for 7 days.

\section{Methods}

The particle size distribution of ground walnut shell was defined by means of vibratory sieve shaker AS 200 (Retsch GmbH, Haan, Germany), equipped with eight sieves with the following mesh size: 0.02, 0.032, 0.063, 0.071, 0.125, 0.25, 0.5 , and $0.8 \mathrm{~mm}$. Measurements were carried out on a loose sample with the mass of $50 \mathrm{~g}$ in time of $1 \mathrm{~h}$. The whole of the mechanically fragmented plant raw material was used for the preparation of the composites, without separating the individual fractions.

The evaluation of geometry and surface structure of ground natural fillers were based on scanning electron microscopy SU-8010 (Hitachi High-Technologies Corp., Tokyo, Japan) photographs analysis. Prior to the tests, all specimens were located on the carbon tape and covered with a layer of gold using sputter coater SC7620 (Quorum Technologies Ltd., Lewes, Great Britain). The electron accelerating 
voltage of $5 \mathrm{kV}$ was applied and the magnifications of $50 \times, 1000 \times, 2000 \times$, and $4500 \times$ were used.

The FT-IR measurements were conducted by means of a Fourier transform spectrometer Vertex 70 (Bruker Corp., Billerica, USA) at an ambient temperature $\left(23{ }^{\circ} \mathrm{C}\right)$. To analyze the ground walnut shell, cured epoxy resin and composites' surfaces and attenuated total reflectance Fourier transform infrared spectroscopy (ATR-FT-IR) were used. In all cases, a total of 64 scans at a resolution of $1 \mathrm{~cm}^{-1}$ was used to record the spectra. All spectra, including the $\mathrm{CO}_{2}$ one, were submitted to weather correction.

Moisture content was determined according to the methodology presented in the ISO 16979 standard, after taking into account the modifications defined in EN 15534-1. Three samples, randomly selected from each batch, weighing about $10 \mathrm{~g}$ each, were placed in the laboratory dryer at a temperature of $103{ }^{\circ} \mathrm{C}\left( \pm 2{ }^{\circ} \mathrm{C}\right)$ until the difference between subsequent weighings, carried out at an interval of $24 \mathrm{~h}$, exceeded $0.1 \%$. The moisture content of the composites was calculated in accordance with the following equation:

$$
H=\frac{m_{0}-m_{1}}{m_{1}} \times 100
$$

where $m_{0}$ - is the initial mass of the test piece $(\mathrm{g}), m_{1}$ - is the mass of the test piece after drying $(\mathrm{g})$.

Mechanical properties of unmodified epoxy resin and epoxy composites were determined in static tensile test according to European standard ISO 527, by means of Zwick Roell Z020 TH ALLround Line universal testing machine (Zwick GmbH \& Co.KG, Ulm, Germany) with $20 \mathrm{kN}$ nominal force. Tests were realized with $5 \mathrm{~mm} / \mathrm{min}$ cross speed. The impact strength of the unnotched samples with $10 \times 4 \times 15 \mathrm{~mm}$ dimensions was measured using Dynstat method (DIN 53453). Hardness evaluation was carried out using Hardness Testing Machine KB 150 R (KB Prüftechnik GmbH, Hochdorf-Assenheim, Germany) in ball indentation hardness test according to ISO 2039 standard. All collected data were statistically elaborated using analysis of variance ANOVA, followed by Scheffe's test using Statistica (data analysis software system) version 10-2011 (StatSoft, Inc., Tulsa, OK, USA).

The DMTA test was performed using MCR 301 rheometer (Anton Paar GmbH, Ostfildern-Scharnhausen, Germany) equipped with a torsion DMA measuring tool. Investigations were carried out with a constant frequency of $1 \mathrm{~Hz}$ and a strain of $0.01 \%$. All samples were evaluated in the temperature range from 20 to $160{ }^{\circ} \mathrm{C}$ with a temperature ramp of $2{ }^{\circ} \mathrm{C} / \mathrm{min}$.

Thermal stability of the filler, unmodified epoxy resin, and epoxy composites were determined by thermogravimetric analysis realized in the temperature range of $30-900{ }^{\circ} \mathrm{C}$ at a heating rate of $10{ }^{\circ} \mathrm{C} / \mathrm{min}$ under nitrogen atmosphere, using a TG 209 F1 Libra apparatus (Erich NETZSCH GmbH \& Co. Holding KG, Selb, Germany). $5 \pm 0.1 \mathrm{mg}$ samples were placed on ceramic pans. The initial decomposition temperature $T_{\mathrm{i}}$ was determined as a temperature at which the weight loss was 5\%. Additionally, thermal decompositions at 10 and $50 \%$ weight loss were presented. The residual mass $(\Delta W \%)$ was defined at $900{ }^{\circ} \mathrm{C}$. 
The samples' fractures were examined and digitally captured using a scanning electron microscope Evo 40 (Carl Zeiss Microscopy GmbH, Jena, Germany). The electron accelerating voltage of $12 \mathrm{kV}$ was applied. Prior to the tests, all specimens were sputtered with a layer of gold. The magnification of $400 \times$ was used.

\section{Results and discussion}

\section{Natural filler analysis}

In Fig. 1, the grain size distribution of ground walnut shell corresponds to the amount of material which remained on a sieve with a specified mesh size. Based on the analysis, it was found that the prepared filler was characterized by a relatively homogeneous size distribution. The analysis of the results allowed to determine that the size of the majority of the constituted particles (95\%) was in the range of 32-125 $\mu \mathrm{m}$.

SEM photographs presented in Fig. 2 showed grains of the natural filler applied in this study after the grinding and drying processes. The particles of ground walnut shell differed in size and geometry (Fig. 2a). A considerable number of grains, despite different roughness of the surface (rough or smooth, Fig. 2c), were characterized by similar spherical shape (Fig. 2b). This filler type may be characterized as particle shaped, moreover, most of WS particles were characterized with developed surface (Fig. 2d).

\section{Evaluation of composite materials' properties and structure}

FT-IR spectra of ground walnut shell, the unmodified epoxy resin sample, and the composite containing $50 \mathrm{wt} \%$ of the filler, were presented in Fig. 3. At WS spectra,

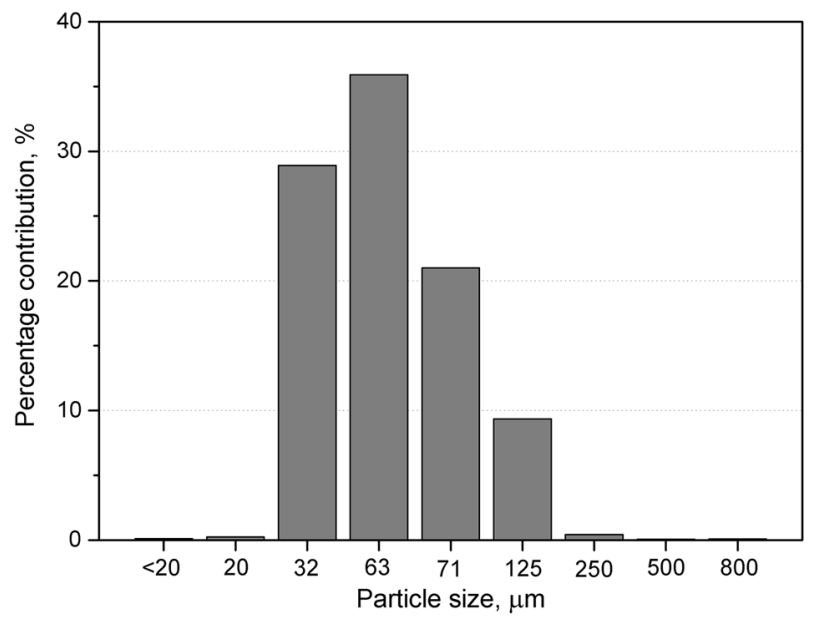

Fig. 1 Particle size distribution of ground walnut shell 

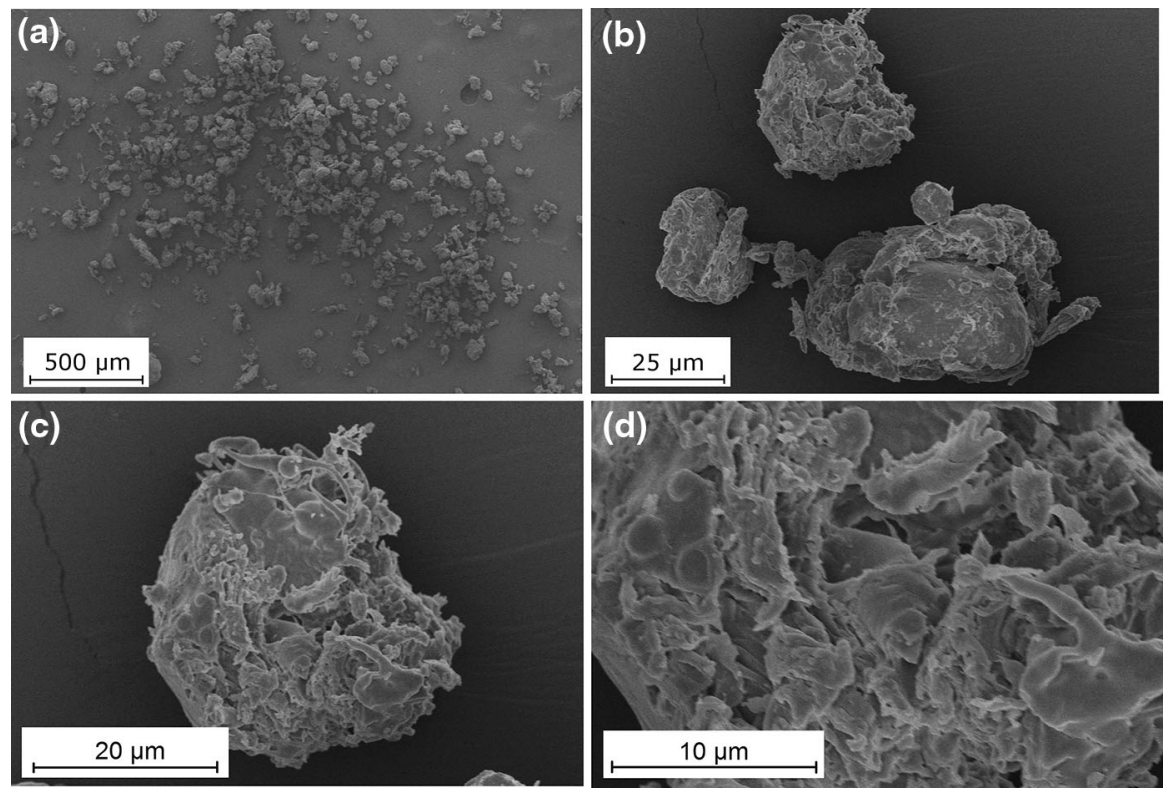

Fig. 2 SEM photographs of ground walnut shell, mag. $\times 50(\mathbf{a}), \times 1000(\mathbf{b}), \times 2000(\mathbf{c})$, and $\times 4500(\mathbf{d})$

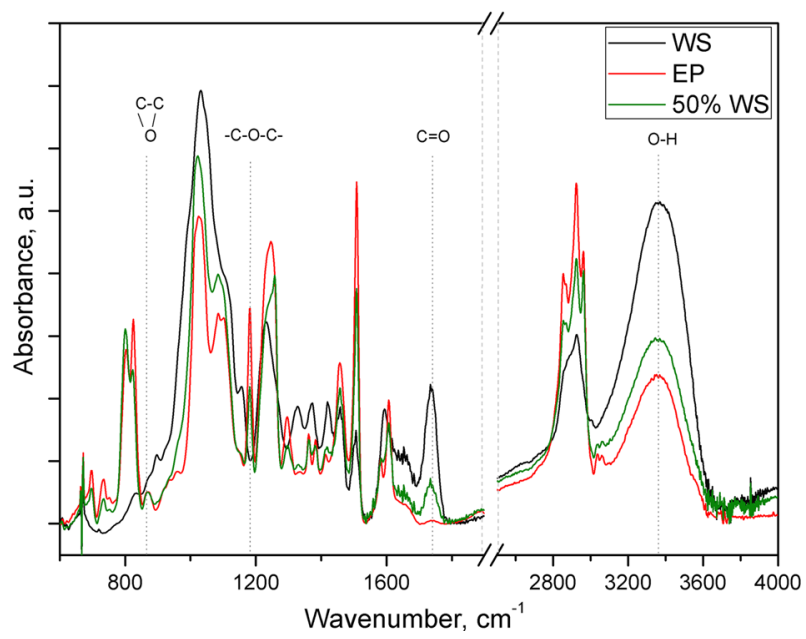

Fig. 3 Absorbance FT-IR spectra of ground walnut shell, cured epoxy resin, and composite 50\% WS in a wavenumber range from 600 to $4000 \mathrm{~cm}^{-1}$

the broad absorption band at $3500 \mathrm{~cm}^{-1}$ indicates bonded hydroxyl $-\mathrm{OH}$ groups existing in the organic filler. Absorption peaks at wavenumbers of around 2900, 1744 , and $1053 \mathrm{~cm}^{-1}$ are assigned to $-\mathrm{CH}, \mathrm{C}=\mathrm{O}$ and $\mathrm{C}-\mathrm{O}$ stretchings, respectively [23]. Moreover, the observed peak at $1623 \mathrm{~cm}^{-1}$ corresponds to $\mathrm{C}=\mathrm{C}$ stretching and confirms the presence of lignin and its aromatic group in the natural filler [24, 25]. 
At epoxy resin and composite sample spectra, vibration band at $915 \mathrm{~cm}^{-1}$, resulting from $\mathrm{C}-\mathrm{O}$ deformation of oxirane group, was recorded. The decrease of this band reflects the development of epoxy groups (a reaction of epoxide rings to form ether linkages). Despite high amount of the filler in the composition, intensities of the unmodified epoxy resin absorbance and of the composite with the highest WS amount were comparable. The increasing peak denoted near $1200 \mathrm{~cm}^{-1}$, corresponding to $\mathrm{C}-\mathrm{O}-\mathrm{C}$ stretching of aliphatic linear ester, was connected with homopolymerization of epoxy groups. The sample containing $50 \mathrm{wt} \%$ of WS showed a strong decrease in absorbance at this intensity, therefore, it can be stated that the curing process was modified by the presence of the organic filler. During epoxy cast curing, epoxide ring opening process is usually accompanied by the occurrence of an increasing peak of the $-\mathrm{OH}$ stretching, at $3500 \mathrm{~cm}^{-1}$. In case of the $50 \%$ WS sample, a higher intensity of the absorbance peak (at $3500 \mathrm{~cm}^{-1}$ ) may be observed than for unmodified epoxy resin [26, 27]. This fact may be attributed both to the presence of the organic filler in the composite material, as well as the effect catalytic reaction of the curing process caused by the presence of additional $-\mathrm{OH}$ groups originating from the filler [28, 29]. Detailed description of all observed at FT-IR spectra peaks was presented in Table 1.

Moisture testing provides information on the amount of water contained in the material. The presence of water in the composites suggests that, despite the drying process performed, certain amount of water was introduced to the NFC. Unfortunately, to realize complete elimination of the water from the natural fillers, it is necessary to use high temperature drying processes $\left(400{ }^{\circ} \mathrm{C}\right)$, which increases production costs and may cause thermal and hydrolytic decomposition of the hemicellulose material [10]. Preliminary drying of the filler and elevated temperature during curing of the epoxy casts should provide to complete removal of moisture from organic particles, therefore, the absorption of moisture from the air during conditioning of the materials cannot be excluded. This is confirmed by the fact that, under real conditions of use, the moisture content of such composites depends on humidity and is subject to seasonal fluctuations (higher values in the summer months) [12]. In Fig. 4 results of moisture content of pure epoxy and composite materials, determined as the loss of its mass between the time of sampling and state after drying to constant mass at $103{ }^{\circ} \mathrm{C}$, were presented. Similar values were measured for all composite samples, whereas the highest moisture content was observed for EP. The high values of investigated parameter denoted for unmodified epoxy resin may be attributed to the release of low molecular weight degradation products of the thermoset polymeric matrix. The thermal stability of epoxy resin and epoxy composites was comprehensively described in the part of the article concerning thermogravimetric analysis. Surprisingly, evaluated parameter was almost at the same level for all composite materials. The stabilization effect of the parameter, measured in accordance to ISO 16979 standard, observed for all composite material is a result of simultaneously decreasing amount of low molecular weight products of epoxy resin degradation, as well as increasing amount of hydrophilic natural waste filler.

Tensile strength and Young's modulus were measured by means of static tensile experiment to assess the influence of an organic filler addition on epoxy composites' 
Table 1 Detailed information about characteristic vibrations observed at FT-IR spectra of ground walnut shell [23-25] and epoxy resin [26-34]

\begin{tabular}{|c|c|c|}
\hline Material & $\begin{array}{l}\text { Band } \\
\left(\mathrm{cm}^{-1}\right)\end{array}$ & Assignment \\
\hline \multirow{11}{*}{$\begin{array}{l}\text { Walnut } \\
\text { shell }\end{array}$} & 3356 & O-H stretching \\
\hline & 2932 & $\mathrm{C}-\mathrm{H}$ stretch in methyl and methylene groups \\
\hline & 1733 & $\mathrm{C}=\mathrm{O}$ stretch in unconjugated ketone, carbonyl and in ester groups \\
\hline & 1623 & $\mathrm{C}=\mathrm{C}$ stretching in aromatic group \\
\hline & 1593 & Aromatic skeletal vibrations $\mathrm{C}=\mathrm{O}$ stretch \\
\hline & 1506 & Aromatic skeletal vibrations \\
\hline & 1458 & $\mathrm{C}-\mathrm{H}$ asymmetrical deformations in $-\mathrm{CH}_{3}$ and $-\mathrm{CH}_{2}-$ \\
\hline & 1421 & Aromatic skeletal vibrations combined with $\mathrm{C}-\mathrm{H}$ in-plane deform \\
\hline & 1371 & Aliphatic $\mathrm{C}-\mathrm{H}$ stretch in $\mathrm{CH}_{3}$ \\
\hline & 1230 & $\mathrm{C}-\mathrm{C}, \mathrm{C}-\mathrm{O}$ and $\mathrm{C}=\mathrm{O}$ stretching \\
\hline & 1031 & $\begin{array}{l}\text { Aromatic } \mathrm{C}-\mathrm{H} \text { in-plane deformation, } \mathrm{C}-\mathrm{O} \text { deform in primary alcohols and } \\
\mathrm{C}=\mathrm{O} \text { stretch }\end{array}$ \\
\hline \multirow{11}{*}{$\begin{array}{l}\text { Epoxy } \\
\text { resin }\end{array}$} & 3369 & $\mathrm{O}-\mathrm{H}$ stretching \\
\hline & 3062 & Stretching of $\mathrm{C}-\mathrm{H}$ of the oxirane ring \\
\hline & 2923,2854 & Bending vibration of $-\mathrm{C}-\mathrm{H}$ in methylene group \\
\hline & 1606,1180 & Stretching vibration of $-\mathrm{C}=\mathrm{C}$ in benzene ring \\
\hline & 1508 & $\mathrm{C}-\mathrm{O}-\mathrm{C}$ stretching \\
\hline & 1456 & $\mathrm{C}=\mathrm{C}$ stretching in aromatic ring \\
\hline & 1296 & Stretching vibration of $\mathrm{C}-\mathrm{N}$ \\
\hline & 1245 & Asymmetrical stretching vibration of $\mathrm{C}-\mathrm{O}-\phi$ \\
\hline & 1026 & Stretching $\mathrm{C}-\mathrm{O}-\mathrm{C}$ of ethers \\
\hline & 915 & Stretching $\mathrm{C}-\mathrm{O}$ of oxirane group \\
\hline & 825 & Out-of-plane bending vibration of $-\mathrm{CH}_{2}$ in epoxide group \\
\hline
\end{tabular}

$\phi$ benzene ring

Fig. 4 Moisture content of pure epoxy resin (EP) and composite samples (WS)

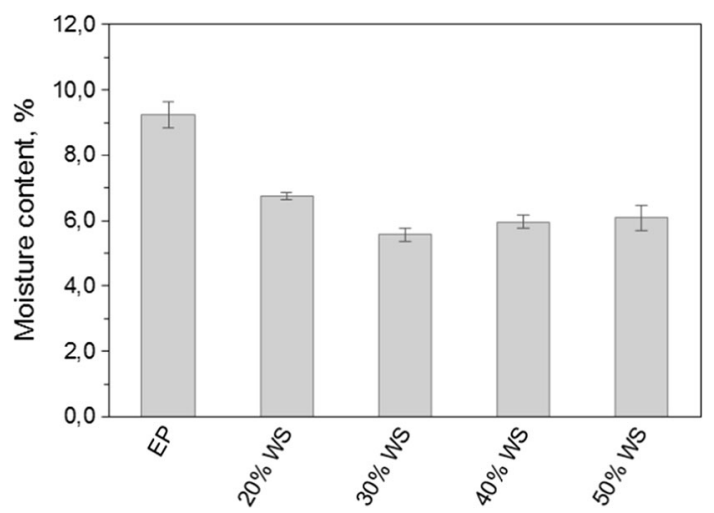


properties. Figure 5a, b showed variations of those two mechanical properties describing samples' behavior as a function of filler amount. The organic filler incorporation into polymeric matrix caused a decrease of tensile strength in comparison to the unmodified polymer. Simultaneously, the values of Young's modulus measured for the samples made of composite materials were significantly higher in comparison to unmodified epoxy resin. Gradual improvement of the sample stiffness was observed for samples containing 20 and $30 \mathrm{wt} \%$. For composite samples modified with $30 \mathrm{wt} \%$ of the filler, the Young's modulus value, mainly $2.0 \mathrm{GPa}$, was almost twice higher in comparison to the reference-unmodified epoxy sample, which reached $1.2 \mathrm{GPa}(p<0.00001)$. However, in case of higher amount of the filler, i.e., above $30 \mathrm{wt} \%$, the elasticity modulus-measured values were lower in comparison to the sample containing $20 \mathrm{wt} \%$ of the filler. Description of NFC for which a fall in the Young's modulus was recorded after exceeding the optimum filler content $50 \mathrm{wt} \%$ can be found in the literature [35]. It can be stated that the improved elasticity modulus is a result of epoxy resin curing process modification. It is well known that any incorporation of a filler, with a surface rich in hydroxyl $-\mathrm{OH}$ groups, may cause an additional catalytic effect resulting in the creation of additional segments of curing network [28]. Therefore, the improved stiffness of the composites containing lower amount of ground walnut shell is
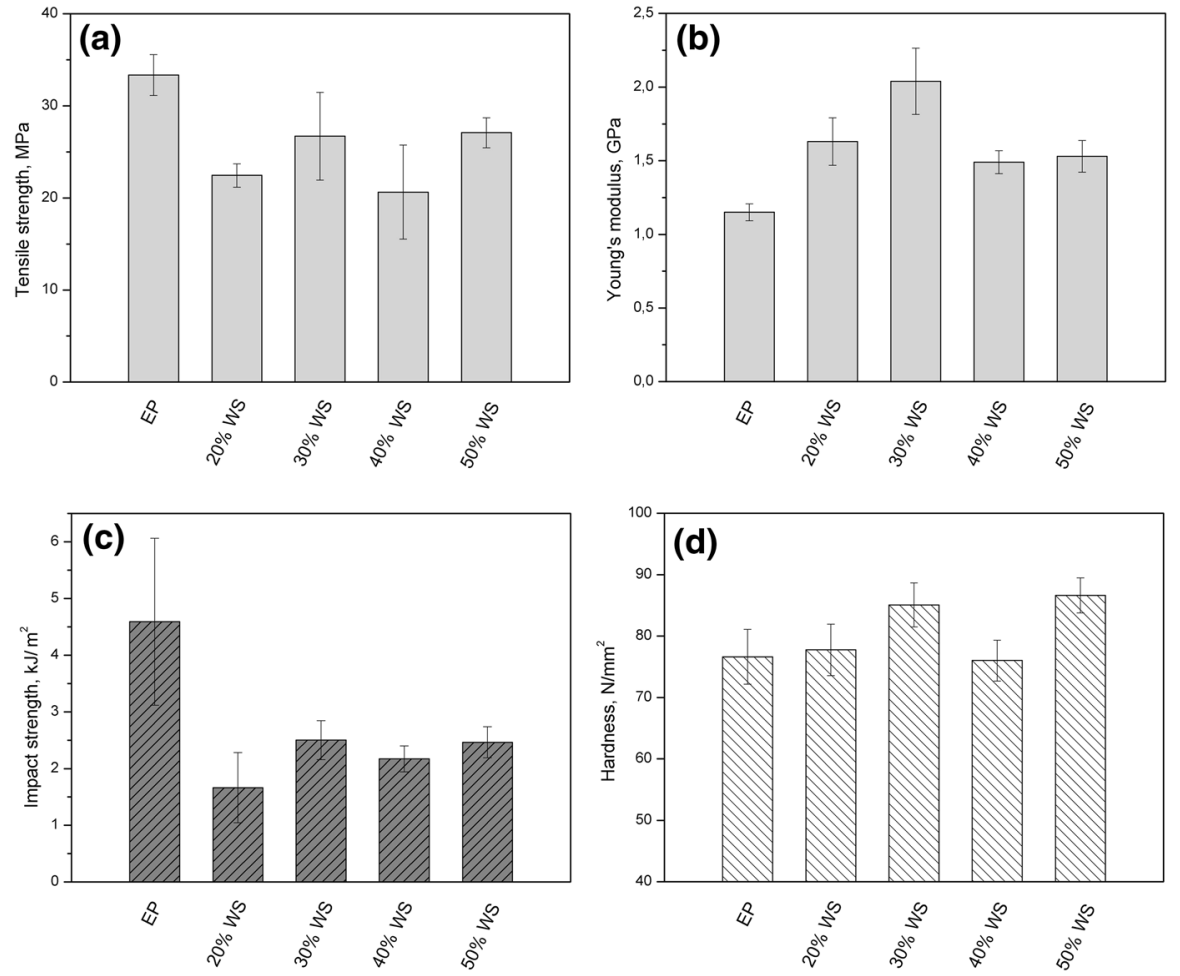

Fig. 5 Mechanical properties of pure epoxy resin (EP) and epoxy composite (WS) samples 
probably caused simultaneously by stiff filler structures' presence, as well as increased cross-linking density of epoxy matrix. The reason for lowering Young's modulus values for composites containing 40 and $50 \mathrm{wt} \%$ of fine ground walnut shell, as compared to the samples which reveal the highest elasticity modulus values, i.e., $30 \mathrm{wt} \% \mathrm{WS}$, could be a random arrangement of filler particles and a hindered degassing of highly viscous compositions. Moreover, it should be mentioned that volumetric share of organic waste filler in polymer matrix was significantly higher then amount calculated by weight. It may be stated that for composites containing more than $30 \mathrm{wt} \%$ of the filler some particles were in a mutual contact. This phenomenon provides to local variations of stress transfer, which caused lowered values of whole composite material elasticity modulus. Lower values of mechanical properties obtained for the composites with the highest share of the filler suggest that the incorporation of high amount of fine ground walnut shell may be reasonable only in case of fabrication of the products that will not be highly loaded during their exploitation. It cannot be excluded that natural rigidity and ability to transfer mechanical loads, resulting from the walnut shell structure, were lost because of the significant level of its fragmentation. The rigidity of polymer composites depends on the shape of the filler. If value of aspect ratio of the filler is close to one, as in the case of a applied ground walnut shell, the amount and elasticity of incorporated filler as well as elasticity of polymeric matrix gain in significance $[35,36]$.

In Fig. 5c the results of the impact strength of epoxy resin and composite materials were depicted. Natural filler incorporation caused a decrease in the impact strength of the composites in comparison to the unmodified polymeric matrix. The lowest impact strength, equal to $1.66 \mathrm{~kJ} / \mathrm{m}^{2}$, was observed for the sample containing $20 \mathrm{wt} \%$ of the WS, while for unmodified epoxy resin, the value was $4.6 \mathrm{~kJ} / \mathrm{m}^{2}$ $(p<0.001)$. This phenomenon is typical for polymeric composites modified by a particle-shaped filler and its insufficient dispersion in polymer matrix [37]. Moreover, it cannot be excluded that residual moisture present in the filler and incorporated to composite material provided micropores that acted as notch during abrupt load in the course of Charpy experiment. It should be mentioned that the measured values of impact strength were not corresponding to higher amount of the filler in composite material.

Hardness measurement results for epoxy resin and composite materials were presented in Fig. 5d. It can be observed that the incorporation of ground walnut shell led to an improvement in the composites' hardness in comparison to the unmodified thermoset polymer. The highest value of $\mathrm{HB}$ hardness was denoted for the composite containing $50 \mathrm{wt} \%$ of the filler, mainly $86.6 \mathrm{~N} / \mathrm{mm}^{2}$, while for unmodified epoxy resin, the value was $76.6 \mathrm{~N} / \mathrm{mm}^{2}(p<0.01)$. However, the lack of a distinct relationship between the filler amount and the composites' hardness may be attributed both to the low hardness of walnut shell itself (2.5-3.5 in Mosh scale), as well as insufficient dispersion in epoxy matrix. According to our previously published results, the hardness of the natural fiber composites with ground sunflower husks and pistachio shell depends on the size of the particles and decreased with increasing fillers content [38]. Moreover, the lack of correlation between the amount of incorporated into polymeric matrix natural filler and 
mechanical properties of the composites was observed also in the case of polyethylene filled with hazelnut shell [39].

In Fig. 6, storage modulus $\left(G^{\prime}\right)$ and loss factor $(\tan \delta)$ curves were presented as a function of temperature $(T)$. It can be clearly observed that the natural waste filler incorporation caused an increase in $G^{\prime}$ in the considered temperature range. The denoted improvement in $G^{\prime}$ value after adding 50\% of WS was equal to 100 and $403 \%$ measured at 30 and $80{ }^{\circ} \mathrm{C}$, respectively, in comparison to unmodified epoxy resin. This means that composite materials reveal a higher ability to maintain mechanical loading with recoverable viscoelastic deformation than unmodified epoxy resin, also in elevated temperature [26, 40]. Changes observed for resin modified with walnut shell particles on the $G^{\prime}$ vs. $T$ curves are in good agreement with the static tensile test results and may be assigned to the improved stiffness of composite materials. However, it should be mentioned that for samples containing more than $20 \mathrm{wt} \%$ of the organic filler, the differences between measured storage modulus values were negligible. In Fig. 6b, loss factor changes were depicted. The unmodified epoxy sample revealed the highest value of $\tan \delta$. With the increasing amount of natural filler particles, the maximum measured loss factor was slightly reduced. This phenomenon is comprehensible because of the incorporation of filler stiff domains which acted as a steric hindrance reducing material attenuation. The glass transition temperature $\left(T_{\mathrm{g}}\right)$ measured as a peak of $\tan \delta$ vs. $T$ curve was lowered with a higher content of the filler. It is probable that residual fat in ground walnut shell plasticized composite materials [41]. However, this effect was not accompanied by $G^{\prime}$ decrease, therefore, it may be stated that the used filler did not modify the curing process in the entire polymer material but only led to a modification of the cross-link density near the organic particles' surface.

Thermal stability of highly filled epoxy composites was evaluated by thermogravimetric analysis to complement the characteristics and to define a potential temperature usability range of final products. The results of TG measurements realized in inert atmosphere are presented in Fig. 7. The additional data on the degradation process, including: 5, 10, and 50\% mass loss temperatures, residual mass, and information on maximum intensity of degradation read from DTG curves for all measured samples, are summarized in Table 2. Based on the change in mass,
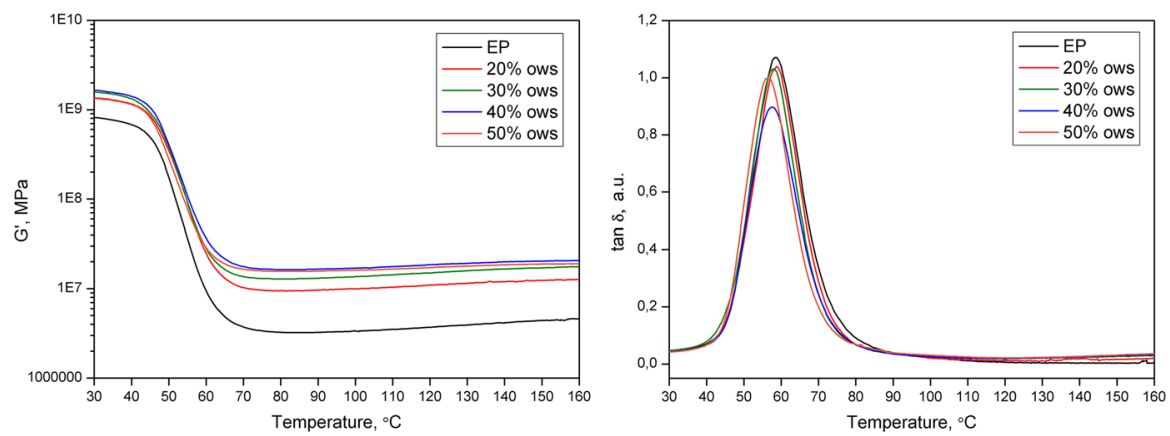

Fig. 6 DMTA curves of $G^{\prime}$ and $\tan \delta$ vs. temperature of unmodified epoxy resin (EP) and epoxy composite (WS) samples 

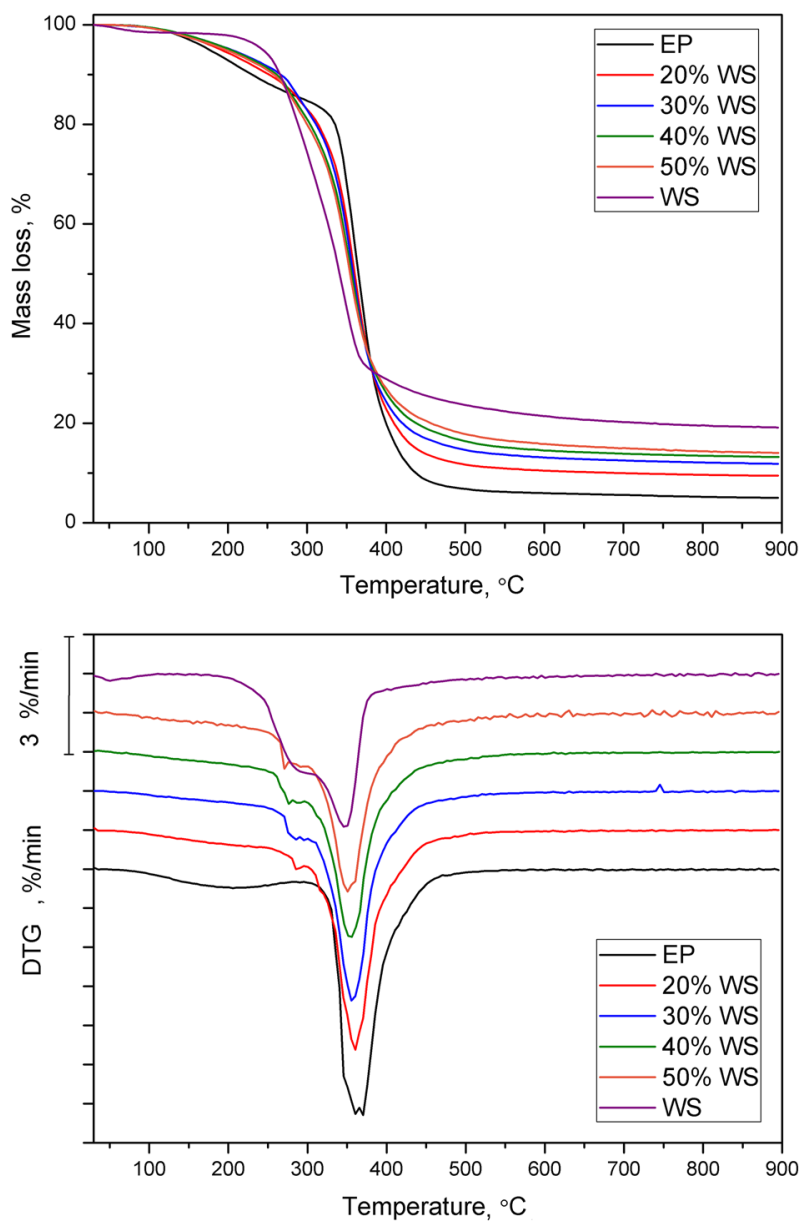

Fig. 7 TG and DTG curves of epoxy resin (EP), epoxy composites (WS), and natural filler

Table 2 TG and DTG data of epoxy resin (EP) and epoxy composites (WS) investigated under nitrogen atmosphere

\begin{tabular}{llllll}
\hline Material & $\begin{array}{l}5 \% \text { mass loss } \\
\left({ }^{\circ} \mathrm{C}\right)\end{array}$ & $10 \%$ mass loss & $50 \%$ mass loss & $\begin{array}{l}\text { Residual mass } \\
(\%)\end{array}$ & $\begin{array}{l}\text { DTG } \\
\left({ }^{\circ} \mathrm{C} ; \% / \mathrm{min}\right)\end{array}$ \\
\hline EP & 177 & 231 & 365 & 5.00 & $371 ;-12.6$ \\
$20 \% \mathrm{WS}$ & 192 & 252 & 360 & 9.44 & $361 ;-11.25$ \\
$30 \% \mathrm{WS}$ & 204 & 267 & 358 & 11.88 & $356 ;-10.7$ \\
$40 \% \mathrm{WS}$ & 203 & 262 & 356 & 13.23 & $356 ;-9.47$ \\
$50 \% \mathrm{WS}$ & 197 & 258 & 354 & 14.06 & $351 ;-9.15$ \\
WS & 244 & 266 & 341 & 19.13 & $345 ;-7.83$ \\
\hline
\end{tabular}


ranging from ambient temperature to $130{ }^{\circ} \mathrm{C}$, it was found that despite the drying process the content of water in the shell reached $1.58 \%$. It is possible that in fillerremained water, which was constantly linked with hydrophilic fiber components by chemical bonds. Natural filler decomposition occurred in the course of a two-step process, while the unmodified epoxy resin took place in a single-step way. The first mass loss of the TG curve observed for walnut shell sample was up to $130{ }^{\circ} \mathrm{C}$ and corresponded to the evaporation of the moisture which was present in the organic material. The next mass loss observed at the natural filler TG and DTG curves began at about $190{ }^{\circ} \mathrm{C}$, rose to the maximum decomposition rate at $345^{\circ} \mathrm{C}$, and finished at about $390{ }^{\circ} \mathrm{C}$. The courses of the WS thermogravimetric curves are similar to those presented in the literature and correspond to decomposition of the three main components of walnut shell: hemicelulose $\left(210-325{ }^{\circ} \mathrm{C}\right), \alpha$-cellulose $\left(310-400{ }^{\circ} \mathrm{C}\right)$, and lignin $\left(160-500{ }^{\circ} \mathrm{C}\right)$ [42-45]. Passive pyrolysis of the natural filler occurs above $470{ }^{\circ} \mathrm{C}$. All composite materials containing walnut shell undergo a two-step decomposition with an increasing intensity during the first step, adequate to the increasing content of ground walnut shell. Because of the possibility of lignocellulose fiber decomposition, due to the temperature increase during the manufacture of the composites, the degradation temperature of the filler $\left(T_{\mathrm{dmax}}\right)$ was determined. $T_{\mathrm{dmax}}$, corresponding to a weight loss of $1 \%$ at temperatures above $150{ }^{\circ} \mathrm{C}$, in presented study reached $215{ }^{\circ} \mathrm{C}$ and was at a similar level to the literature data [18]. A comparison of the values shown in Table 2 allows to ascertain that the natural filler has a significantly higher thermal stability in the range of $10 \%$ mass loss than unmodified epoxy resin. Therefore, it is comprehensible that composite materials containing walnut shell particles have higher thermal stability in a temperature range up to $355^{\circ} \mathrm{C}$. The sample containing $30 \mathrm{wt} \%$ of ground walnut shell revealed the highest thermal stability based on 5 and $10 \%$ mass loss. The difference between composite materials with various amounts of WS results from higher natural filler amount in comparison to the $20 \% \mathrm{WS}$ sample, and better dispersion in comparison to samples filled with 40 and $50 \mathrm{wt} \%$ of ground walnut shell. It should be mentioned that thermal degradation of all composite materials was significantly suppressed. The lowest improvement in thermal stability, measured as temperature of $5 \%$ mass loss, was $15^{\circ} \mathrm{C}$, while the highest was $27{ }^{\circ} \mathrm{C}$ for samples containing 20 and $30 \mathrm{wt} \%$ of the filler, respectively. At a measuring point recorded at $50 \%$ mass loss, a different tendency may be observed. The highest temperature was denoted for epoxy resin, whereas the increasing content of WS caused a gradual decrease of 50\% mass loss temperature. Measured at $900{ }^{\circ} \mathrm{C}$, the sample residual mass grew with the increasing content of the organic filler. DTG data indicate that composite decomposition rate was lower than for unmodified epoxy resin, however, the maximum intensity temperature of composite thermal degradation decreased as a function of an increasing organic filler content.

The analysis of epoxy composites' structures was carried out on the basis of the scanning electron microscope photographs. Images of sample fractures taken at $400 \times$ magnification were summarized in Fig. 8. The microstructure of composites containing various amounts of the filler allowed to observe a good saturation of organic particles' surface by polymeric matrix. The application of thermoset material characterized by a relatively low molecular weight favorably influenced the 


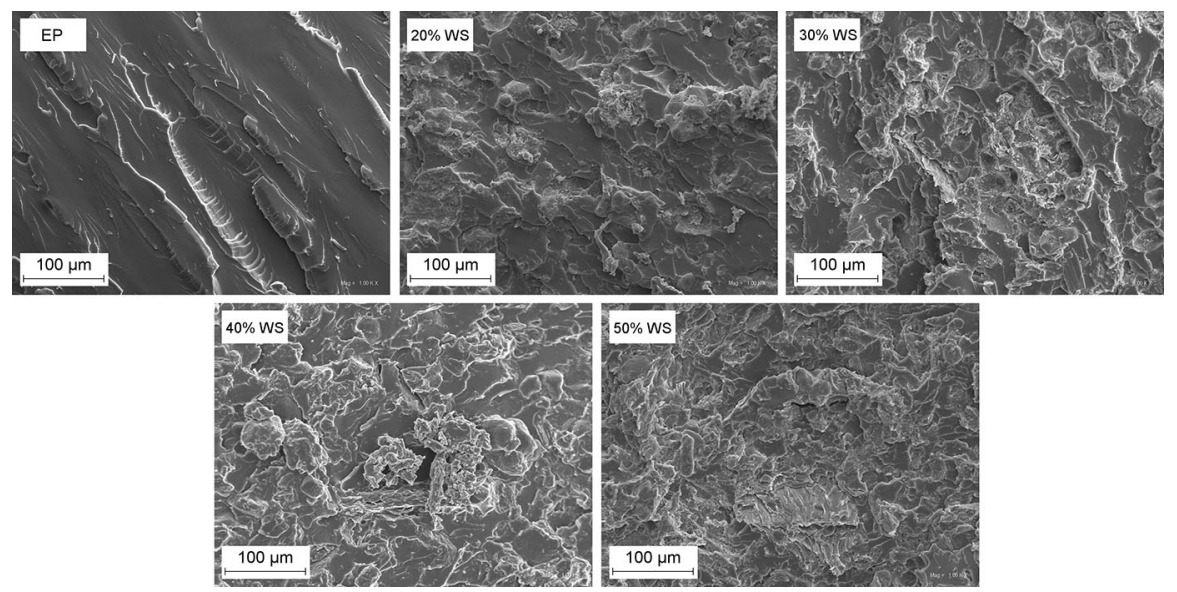

Fig. 8 SEM photographs of pure epoxy resin (EP) and epoxy composite (WS) breakthroughs, mag. $\times 400$

wettability of the filler particles' surface and increased interfacial adhesion between polymer and reinforcement. This phenomenon may be confirmed by the observation of fractured fragments of walnut shell particles instead of entire ones in polymeric matrix. The fractures are caused by a pull-out effect occurring when there are limited interactions in the interface. It should also be noted that the amount of voids resulting from the contact between the resin and the filler was small. The voids were distributed mainly in the polymeric matrix which may be an effect of a hindered degassing of the highly viscous compositions. SEM photographs allowed to observe the filler particles with size of several dozens to more than $100 \mu \mathrm{m}$ in the case of the material containing the highest amount of the WS. It cannot be unequivocally stated that large grain sizes predominate in the case of high-filled composites, since a fragment of the shell of approximately $100 \mu \mathrm{m}$ can be found in the photographs of the WS 30\%. The occurrence of varied sizes and shapes of grains is adequate to the SEM photographs of the filler before it is introduced into the polymer. It can be presumed that the method of mixing the components did not cause further shredding of the shells. SEM analysis allowed to ascertain that the previously described negative effect of the natural filler incorporation on the mechanical properties of the composites may be attributed to a random arrangement of filler particles.

\section{Conclusions}

Post-agricultural organic waste was applied as a filler to modify epoxy resin composites. The incorporation of ground walnut shell into polymeric matrix resulted in a complex modification of mechanical and thermo-mechanical properties of the composites. Epoxy composites containing natural fillers showed significantly improved stiffness and hardness together with a decreased tensile and impact 
strength. The use of thermoset epoxy resin as composite matrix had a beneficial effect on the wettability of the organic filler surface which resulted in a better adhesion of the components, as confirmed by the microstructure analysis carried out with scanning electron microscopy. The improved stiffness and hardness of the composites were related to the reinforcing effect caused by the presence of ground walnut stiff domains, as well as to the modified curing process of epoxy composites. Measurements carried out in the course of dynamic mechanical thermal analysis showed an improved thermo-mechanical stability of the composite materials within the complete temperature range $\left(30-140{ }^{\circ} \mathrm{C}\right)$. Moreover, the ground walnut shell incorporation led to an increase in thermal stability of the composites in comparison to unmodified epoxy resin, which was found after thermogravimetric analysis had been carried out.

To summarize, it was proved that the incorporation of high amounts of finely ground walnut shell into thermoset polymer allows to prepare low-cost composites with acceptable mechanical and thermo-mechanical properties and make them applicable as materials for low-demanding parts and applications. In reference to changes of mechanical properties and thermal stability, the most favorable filler content for developed epoxy-based composited was $30 \mathrm{wt} \%$. However, with regard to economic considerations, it also seems reasonable to manufacture high-filled composites containing $50 \mathrm{wt} \%$ of a ground walnut shell, especially in the case of non-structural applications.

Acknowledgements The publication prepared on the results of the research task carried out under the statutory activities of the Central Institute for Labour Protection - National Research Institute.

Open Access This article is distributed under the terms of the Creative Commons Attribution 4.0 International License (http://creativecommons.org/licenses/by/4.0/), which permits unrestricted use, distribution, and reproduction in any medium, provided you give appropriate credit to the original author(s) and the source, provide a link to the Creative Commons license, and indicate if changes were made.

\section{References}

1. Han SJ, Lee H, Jeong HM, Kim BK, Raghu AV, Reddy KR (2014) Graphene modified lipophilically by stearic acid and its composite with low density polyethylene. J Macromol Sci Phys 53:1193-1204. doi:10.1080/00222348.2013.879804

2. Reddy KR, Sina BC, Ryua KS, Kimb JC, Chungc H, Lee Y (2009) Conducting polymer functionalized multi-walled carbon nanotubes with noble metal nanoparticles: synthesis, morphological characteristics and electrical properties. Synth Met 159:595-603. doi:10.1016/j.synthmet.2008.11. 030

3. Choi SH, Kim DH, Raghu AV, Reddy KR, Lee H, Yoon KS, Jeong HM, Kim BK (2012) Properties of graphene/waterborne polyurethane nanocomposites cast from colloidal dispersion mixtures. J Macromol Sci Phys 51:197-207. doi:10.1080/00222348.2011.583193

4. Salasinska K, Polka M, Gloc M, Ryszkowska J (2016) Composites with pistachio shell and sunflower husk: the effect of filler content and chemical constitution on the dimensional and fire stability. Polimery-W 61:255-265. doi:10.14314/polimery.2016.255

5. Blędzki AK (1997) Recycling of polymeric materials. Scientific Publishers PWN, Warsaw

6. Carus M, Ortmann S, Gahle CH, Pendarovski C (2006) Use of natural fibers in composites for the German automotive production from 1999 till 2005. Nova-Institut, Hurth 
7. Wambua P, Ivens J, Verpoest I (2003) Natural fibers: can they replace glass in fiber reinforced plastics? Compos Sci Technol 53:1259-1264. doi:10.1016/S0266-3538(03)00096-4

8. Holbery J, Houston D (2006) Natural-fiber-reinforced polymer composites in automotive applications, overview low-cost composites in vehicle manufacture. JOM 58:80-86

9. Shah DU (2013) Developing plant fibre composites for structural applications by optimizing composite parameters: a critical review. J Maters Sci 48:6083-6107. doi:10.1007/s10853-013-7458-7

10. Kuciel S, Rydarowski H (2012) Biocomposies from renewable resources. Cracow University of Technology, Cracow

11. Faruk O, Bledzki AK, Fink HP, Sain M (2012) Biocomposites reinforced with natural fibers: 2000-2010. ProgPolym Sci 37:1552-1596. doi:10.1016/j.progpolymsci.2012.04.003

12. Klyosov AA (2007) Wood-plastic composites, 1st edn. Wiley, Hoboken, New Jersey

13. Salasinska K, Ryszkowska J (2013) Dimensional stability, physical, mechanical and thermal properties of high density polyethylene with peanut hulls composites. Polimery-W 58:461-466. doi:10. 14314/polimery.2013.461

14. Salasinska K, Ryszkowska J (2012) Natural fibre composites from polyethylene waste and hazelnut shell: dimensional stability, physical, mechanical and thermal properties. Compos Interface 19:321-332. doi:10.1080/15685543.2012.726156

15. Carus M, Eder A, Dammer L, Korte H, Scholz L, Essel R, Breitmayer E (2013) Wood-plastic composites (WPC) and natural-fibre composites (NFC): European and global markets 2012 and future trends. nova-Institut $\mathrm{GmbH}$, Huerth

16. Pirayesh H, Khazaeian A (2012) Using almond (Prunus amygdalus L.) shel as bio-waste resource in wood based composites. Compos Part B-Eng 43:1475-1479. doi:10.1016/j.compositesb.2011.06.008

17. Nishikawa Y, Nagase N, Fukushima K (2009) Application of peanut hulls as filler for plastics. J Environ Eng 4:124-134. doi:10.1299/jee.4.124

18. Bledzki AK, Mamun AA, Volk J (2010) Barley husk and coconut shell reinforced polypropylene composites: the effect of fibre physical, chemical and surface properties. Compos Sci Technol 70:840-846. doi:10.1016/j.compscitech.2010.01.022

19. Ayrilmis N, Kaymanakci A, Ozdemir F (2013) Physical, mechanical, and thermal properties of polypropylene composites filled with walnut shell flour. J Ind Eng Chem 19:908-914. doi:10.1016/j. jiec.2012.11.006

20. Zahedi M, Pirayesh H, Khanjanzadeh H, Tabar MM (2013) Organo-modified montmorillonite reinforced walnut shell/polypropylene composites. Mater Design 51:803-809. doi:10.1016/j.matdes. 2013.05.007

21. Mohammed AJ (2014) Study the effect of adding powder walnut shells on the mechanical properties and flame resistance for low density polyethylene (LDPE). Int J Sci Technol 3:18-22

22. Singh VK (2013) Mechanical behavior of walnut (Juglans L.) shell particles reinforced bio-composite. Sci Eng Compos Mater 22:383-390

23. Lee YR, Kim SC, Lee H, Jeong HM, Raghu AV, Reddy KR, Kim BK (2011) Graphite oxides as effective fire retardants of epoxy resin. Macromol Res 19:66-71. doi:10.1007/s13233-011-0106-7

24. Farhan AM, Salem NM, Al-Dujali AH, Awwad AM (2012) Biosorption studies of Cr(VI) ions from electroplating wastewater by walnut shell powder. Am J Environ Eng 2:188-195. doi:10.5923/j.ajee. 20120206.07

25. Mukome FND, Zhang X, Silva LCR, Six J, Parikh SJ (2013) Use of chemical and physical characteristics to investigate trends in biochar feedstocks. J Agric Food Chem 61:2196-2204. doi:10. 1021/jf3049142

26. Chmielewska D, Sterzyński T, Dudziec B (2014) Epoxy compositions cured with aluminosilsesquioxanes: thermomechanical properties. J Appl Polym Sci. doi:10.1002/APP.40672

27. Fraga F, Vazquez EC, Rodriguez-Nunez E, Martinez-Ageitos JM (2008) Curing kinetics of the epoxy system diglycidyl ether of bisphenol A/isophoronediamine by Fourier transform infrared spectroscopy. Polym Adv Technol 19:1623-1628. doi:10.1002/pat.1178

28. Baller J, Thomassey M, Ziehmer M, Sanctuary R (2011) The catalytic influence of alumina nanoparticles on epoxy curing. Thermochim Acta 517:34-39. doi:10.1016/j.tca.2011.01.029

29. Rozenberg BA (1986) Kinetics, thermodynamics and mechanism of reactions of epoxy oligomers with amines. Adv Polym Sci 75:113-165. doi:10.1007/BFb0017916

30. Liu F, Yin M, Xiong B, Zheng F, Mao W, Chen Z, He C, Zhao X, Fang P (2014) Evolution of microstructure of epoxy coating during UV degradation progress studied by slow positron annihilation spectroscopy and electrochemical impedance spectroscopy. Electrochim Acta 133:283-293. doi:10.1016/j.electacta.2014.04.002 
31. Menzheres GYA, Yarovaya NB, Degryareva AA, Magdinets VV (1994) Conversions in epoxyanhydride system initiated by a photogenerated donor-acceptor complex. Theor Exp Chem 30:191-194. doi:10.1007/BF00534662

32. Domenech-Carbo MT, Domenech-Carbo A, Gimeno-Adelantado JV, Bosch-Reig F (2001) Identification of synthetic resins used in works of art by Fourier transform infrared spectroscopy. Appl Spectrosc 55:1590-1602. doi:10.1366/0003702011954152

33. Bratychak M, Bruzdziak P, Namieśnik J (2016) Synthesis and properties of carboxy derivative of Epidian 6 monomethacrylate. Polimery-W 61:766-772. doi:10.14314/polimery.2016.766

34. Allen RO, Sanderson P (1998) Characterization of epoxy glues with FTIR. Appl Spectrose Rev 24:175-187. doi:10.1080/05704928808060457

35. Balasuriya PW, Ye L, Mai YW (2001) Mechanical properties of wood flake-polyethylene composites. Part I: effects of processing methods and matrix melt flow behavior. Compos Part A Appl S 32:619-629

36. Fu SY, Feng XQ, Lauke B, Mai YW (2008) Effect of particle size, particle/matrix interface adhesion and particle loading on mechanical properties of particulate-polymer composites. Compos Part B Eng 39:933-961. doi:10.1016/j.compositesb.2008.01.002

37. SvehlovaV Poloucek E (1987) About the influence of filler particle size on toughness of filled polypropylene. Angew Makromol Chem 153:197-200

38. Salasinska K, Ryszkowska J (2015) The effect of filler chemical constitution and morphological properties on the mechanical properties of natural fiber composites. Compos Interfaces 22:39-50. doi:10.1080/15685543.2015.984521

39. Salasinska K, Ryszkowska J (2012) Physico-mechanical properties and dimensional stability of natural fibre composites fabricated from polyethylene waste and walnut shells. Conference paper ECCM-15th, https://www.researchgate.net/profile/Kamila_Salasinska/publication/287941233_ Physico-mechanical_properties_and_dimensional_stability_of_natural_fibre_composites_fabricated_ from_polyethylene_waste_and_walnut_shells/links/5682fb5808ae19758391c22c.pdf. Accessed 5 July 2017

40. Shakuntala O, Raghavendra G, Kumar AS (2014) Effect of filler loading on mechanical and tribological properties of wood apple shell reinforced epoxy composite. Adv Mater Sci Eng. doi:10.1155/ 2014/538651

41. Czub P, Franek I (2013) Epoxy resins modified with palm oil derivatives-preparation and properties. Polimery-W 58:135-139. doi:10.14314/polimery.2013.135

42. Açikalin K (2011) Thermogravimetric analysis of walnut shell as pyrolysis feedstock. J Therm Anal Calorim 105:145-150. doi:10.1007/s10973-010-1267-x

43. Uzun BB, Yaman E (2014) Thermogravimetric characteristics and kinetics of scrap tyre and Juglans regia shell co-pyrolysis. Waste Manag Res 32:961-970. doi:10.1177/0734242X14539722

44. Błędzki AK, Abdullah AM, Volk J (2010) Physical, chemical and surface properties of wheat husk, rye husk and soft wood their polypropylene composites. Compos Part A Appl S41:480-488. doi:10. 1016/j.compositesa.2009.12.004

45. Manfredi LB, Rodriquez ES, Wladyka-Przybylak M, Vazquez A (2006) Thermal degradation and fire resistance of unsaturated polyester, modified acrylic resins and their composites with natural fibers. Polym Degrad Stabil 91:255-261 